\title{
The Metabolism of Cholestanol, Cholesterol, and Bile Acids in Cerebrotendinous Xanthomatosis
}

\author{
Geraid Salen and Scott M. Grundy \\ From Gastroenterology Section, New York Veterans Administration Hospital, \\ Department of Medicine, New York University School of Medicine, New York \\ 10010 and University of California, San Diego School of Medicine, \\ La Jolla, California 92037
}

A B S T R A C T The metabolism of cholesterol and its 5-dihydro derivative, cholestanol, was investigated by means of sterol balance and isotope kinetic techniques in 3 subjects with cerebrotendinous xanthomatosis (CTX) and 11 other individuals. All subjects were hospitalized on a metabolic ward and were fed diets practically free of cholesterol and cholestanol. After the intravenous administration of $\left[1,2{ }^{3} \mathrm{H}\right]$ cholestanol, the radioactive sterol was transported and esterified in plasma lipoproteins in an identical manner to cholesterol. In these short-term experiments, the specific activity-time curves of plasma cholestanol conformed to two-pool models in both the CTX and control groups. However, cholestanol plasma concentrations, total body miscible pools, and daily synthesis rates were two to five times greater in the CTX than control individuals. The short-term specific activity decay curves of plasma $\left[4-{ }^{14} \mathrm{C}\right]$ cholesterol also conformed to two-pool models in both groups. However, in the CTX subjects the decay was more rapid, and daily cholesterol synthesis was nearly double that of the control subjects. Plasma concentrations and the sizes of the rapidly turning over pool of exchangeable cholesterol were apparently small in the CTX subjects, and these measurements did not correlate with the large cholesterol deposits found in tendon and tuberous xanthomas.

Despite active cholesterol synthesis, bile acid formation was subnormal in the CTX subjects. However, bile acid sequestration was accompanied by a rise in plasma cholestanol levels and greatly augmented fecal choles-

Dr. Salen is a recipient of a Clinical Investigatorship Award from the Veterans Administration, Washington, D. C. His present address is Veterans Administration Hospital, East Orange, N. J. 07019.

Received for publication 23 January 1973 and in revised form 27 June 1973. tanol outputs. In contrast, the administration of clofibrate lowered plasma cholesterol levels $50 \%$ and presumably reduced synthesis in the CTX subjects. Plasma cholesterol concentrations and fecal steroid excretion did not change significantly during this therapy.

These findings indicate that the excessive tissue deposits of cholesterol and cholestanol that characterize CTX were associated with hyperactive neutral sterol synthesis. The demonstration of subnormal bile acid formation suggests that defective bile acid synthesis may predispose to the neutral sterol abnormalities.

\section{INTRODUCTION}

The occurrence of tendon xanthomatosis has long been recognized as a manifestation of severe hypercholesterolemia (Type II, hyperbetalipoproteinemia) and usually signifies that plasma concentrations are in excess of $300 \mathrm{mg} / 100 \mathrm{ml}(1-3)$. However, in the rare inherited disease, cerebrotendinous xanthomatosis (CTX), ${ }^{1}$ histologically similar xanthomas develop, but plasma cholesterol concentrations are remarkably low $(4,5)$. Other features that distinguish CTX from primary hyperbetalipoproteinemia include progressive neurologic dysfunction, cataracts, mild pulmonary insufficiency, and the development of xanthomatous lesions in the brain and lung; coronary atherosclerosis is common to both conditions (6). In 1968 Menkes, Schimschock, and Swanson (7) noted that brain tissue in CTX contained ex-

\footnotetext{
${ }_{1}^{1}$ Abbreviations used in this paper: $\mathrm{AgNO}_{3}$-TLC, argentation thin-layer chromatography; CTX, cerebrotendinous xanthomatosis; HDL, high density lipoproteins; LDL, low density lipoproteins; $M_{A}$, size of pool with rapid turnover; $\mathrm{M}_{\mathbf{B}}$, size of pool with slow turnover; $\mathrm{PR}_{\mathbf{A}}$, production rate; TMS, trimethylsilyl; VLDL, very low density lipoproteins.
} 
TABLE I

Clinical Data

\begin{tabular}{|c|c|c|c|c|c|c|c|c|}
\hline \multirow[b]{2}{*}{ Patients } & \multirow[b]{2}{*}{ Age } & \multirow[b]{2}{*}{ Sex } & \multirow[b]{2}{*}{ Weight } & \multirow[b]{2}{*}{ Height } & \multirow[b]{2}{*}{$\begin{array}{c}\% \\
\text { Ideal* } \\
\text { weight }\end{array}$} & \multicolumn{2}{|c|}{ Plasma lipids } & \multirow[b]{2}{*}{ Clinical diagnosis } \\
\hline & & & & & & $\begin{array}{c}\text { Total } \\
\text { choles- } \\
\text { terol }\end{array}$ & $\begin{array}{c}\text { Tri- } \\
\text { glycer- } \\
\text { ides }\end{array}$ & \\
\hline & & & $\mathrm{kg}$ & $\mathrm{cm}$ & & \multicolumn{2}{|c|}{$\mathrm{mg} / 100 \mathrm{ml}$} & \\
\hline E. D. E. & 46 & $\mathrm{~F}$ & 59 & 169 & 96 & 95 & 82 & CTX \\
\hline 2. J. C. & 32 & $\mathrm{M}$ & 55 & 165 & 95 & 108 & 42 & CTX \\
\hline 3. E. D. S. $\ddagger$ & 46 & $\mathrm{~F}$ & 47 & 161 & 94 & 87 & 62 & CTX \\
\hline 4. G. S. & 73 & M & 59 & 159 & 100 & 242 & 90 & Normolipidemia \\
\hline 5. M. S. & 37 & $\mathrm{M}$ & 54 & 167 & 93 & 300 & 65 & IHD, \& xanthomatosis, hypercholesterolemia (Type II) \\
\hline 6. G. W. & 48 & M & 81 & 173 & 114 & 510 & 132 & Xanthomatosis, hypercholesterolemia (Type II) \\
\hline 7. J. T. & 71 & $\mathrm{M}$ & 73 & 167 & 108 & 244 & 150 & Normolipidemia \\
\hline B. Mc. & 58 & $\mathrm{~F}$ & 64 & 163 & 118 & 259 & 202 & IHD, hypercholesterolemia (Type II) \\
\hline H. T. & 60 & M & 46 & 162 & 84 & 306 & 166 & Hypercholesterolemia (Type II) \\
\hline 10. R. P. & 48 & M & 63 & 165 & 105 & 206 & 421 & Hypertriglyceridemia (Type IV) \\
\hline 11. R. M. & 56 & M & 79 & 177 & 110 & 248 & 153 & Normolipidemia \\
\hline 12. E. S. & 52 & M & 64 & 163 & 106 & 262 & 145 & Hypercholesterolemia (Type II) \\
\hline 13. I. G. & 46 & $\mathrm{~F}$ & 56 & 155 & 112 & 172 & 158 & Normolipidemia \\
\hline 14. J. Ca. & 45 & $M$ & 65 & 176 & 100 & 328 & 206 & IHD, hypercholesterolemia (Type II) \\
\hline
\end{tabular}

* According to life insurance tables of weight for height, age, and sex (9).

$\ddagger$ Sisters, D. family (6).

$\S I H D$, ischemic heart disease.

I Hyperlipoproteinemia was diagnosed by paper-strip electrophoresis according to Fredrickson, Levy, and Lees (3).

traordinary amounts of cholestanol, ${ }^{2}$ the $5 \alpha$-dihydro derivative of cholesterol.

In subsequent studies, we have confirmed the high content of cholestanol in CTX brain but have detected also 10-100 times more cholestanol in 12 other tissues from a CTX subject (6). Although trace amounts of this sterol are found in practically all mammalian tissues (8), the demonstration of such large amounts of cholestanol throughout the body in CTX suggests a role for this sterol in the pathogenesis of the disease. Furthermore, tissue cholesterol levels were $30 \%$ higher than normal, which indicated an associated defect in cholesterol metabolism (6).

In the present study, cholesterol and cholestanol metabolisms were examined simultaneously in three CTX subjects by sterol balance and isotope kinetic methods. Similar studies were performed in 11 other individuals for comparison. Our results in the subjects with CTX showed that the synthesis rates for cholesterol and cholestanol were augmented and suggested that overproduction of these sterols was responsible for the development of elevated tissue concentrations.

${ }^{2}$ The following systematic names are given to sterols referred to by trivial names: cholestanol, $5 \alpha$-cholestan- $3 \beta$ ol ; cholesterol, cholest-5-en-3 $\beta$-ol ; $\Delta^{7}$-cholestenol, $5 \alpha$-cho-

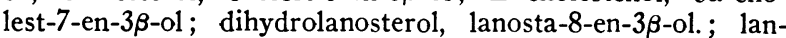
osterol, lanosta-8,24-dien-3 $\beta$-ol.

\section{METHODS}

\section{Clinical aspects}

Studies were carried out on the metabolic ward at the Rockefeller University Hospital and at the Manhattan Veterans Administration Hospital. The age, sex, and body build, plasma lipid levels, and clinical diagnosis of each patient are given in Table I. The three patients with CTX were from two families. Patients 1 and 3 were sisters, and both exhibited moderate neurological impairment, Achilles tendon xanthomas, and low plasma cholesterol concentrations. Patient 2 manifested no evidence of neurologic dysfunction but had large Achilles tendon xanthomas, mild pulmonary insufficiency, and a low plasma cholesterol concentration. Complete clinical descriptions have been published elsewhere $(6,10,11) .11$ additional patients were studied for comparison and exhibited a mixed group of lipid abnormalities including two cases of xanthomatosis.

\section{Diets}

Food intakes in patients 1 through 8,13 , and 14 consisted exclusively of orally administered liquid formula feedings in which protein contributed $15 \%$, fat $40 \%$, and glucose $45 \%$ of the total caloric intake; vitamins and mineral supplements were given as described previously (12). The fat content of each formula is listed in Table II and consisted exclusively of cottonseed oil in patients 1-8 and corn oil in patients 13 and 14 . These fats do not contain cholesterol, but cottonseed oil contains approximately $3.2 \mathrm{mg} \beta$-sitosterol/g and corn oil contains $1.9 \mathrm{mg} \beta$-sitosterol/g. Samples of each formula diet were analyzed repeatedly for sterol content as tests of formula homo- 
TABLE II

Diets and Isotopic Sterols and Duration of Experiment

\begin{tabular}{|c|c|c|c|c|}
\hline Patient & Diet-type of fat & $\begin{array}{c}\text { Radioactive sterol } \\
\text { isotope-sterol/dose }\end{array}$ & $\begin{array}{l}\text { Length of } \\
\text { isotopic } \\
\text { study }\end{array}$ & $\begin{array}{l}\text { Number of } \\
\text { sp act } \\
\text { determina- } \\
\text { tions }\end{array}$ \\
\hline & & & days & $d p m / m g$ \\
\hline \multirow[t]{2}{*}{1} & \multirow[t]{2}{*}{ Formula-cottonseed oil } & {$\left[{ }^{3} \mathrm{H}\right]$ cholestanol $/ 40$} & 28 & 11 \\
\hline & & {$\left[{ }^{14} \mathrm{C}\right]$ cholesterol $/ 45$} & 49 & 21 \\
\hline \multirow[t]{2}{*}{2} & \multirow[t]{2}{*}{ Formula-cottonseed oil } & {$\left[{ }^{3} \mathrm{H}\right]$ cholestanol $/ 28$} & 28 & 17 \\
\hline & & {$\left[{ }^{14} \mathrm{C}\right]$ cholesterol $/ 29$} & 35 & 16 \\
\hline 3 & Formula-cottonseed oil & - & - & - \\
\hline \multirow[t]{2}{*}{4} & \multirow[t]{2}{*}{ Formula-cottonseed oil } & {$\left[{ }^{3} \mathrm{H}\right]$ cholestanol $/ 28$} & 42 & 13 \\
\hline & & {$\left[{ }^{14} \mathrm{C}\right]$ cholesterol $/ 135$} & 70 & 15 \\
\hline 5 & Formula-cottonseed oil & {$\left[{ }^{14} \mathrm{C}\right]$ cholesterol $/ 135$} & 56 & 15 \\
\hline 6 & Formula-cottonseed oil & {$\left[{ }^{14} \mathrm{C}\right]$ cholesterol $/ 135$} & 49 & 13 \\
\hline 7 & Formula-cottonseed oil & {$\left[{ }^{14} \mathrm{C}\right]$ cholesterol $/ 135$} & 56 & 15 \\
\hline 8 & Formula-cottonseed oil & {$\left[{ }^{14} \mathrm{C}\right]$ cholesterol $/ 135$} & 49 & 13 \\
\hline 9 & Solid food-unsaturated fat & {$\left[{ }^{3} \mathrm{H}\right]$ cholestanol $/ 36$} & 36 & 11 \\
\hline 10 & Solid food-unsaturated fat & {$\left[{ }^{3} \mathrm{H}\right]$ cholestanol $/ 26$} & 36 & 11 \\
\hline 11 & Solid food-unsaturated fat & {$\left[{ }^{3} \mathrm{H}\right]$ cholestanol $/ 26$} & 36 & 11 \\
\hline 12 & Solid food-unsaturated fat & {$\left[{ }^{3} \mathrm{H}\right]$ cholestanol $/ 36$} & 36 & 10 \\
\hline 13 & Formula-corn oil & - & - & - \\
\hline 14 & Formula-corn oil & - & - & - \\
\hline
\end{tabular}

geneity. They contained only small amounts of cholesterol and no cholestanol. Based upon these analyses, the subjects ingested less than $45 \mathrm{mg} /$ day of cholesterol.

Patients 9-12 ate low-cholesterol unsaturated fat diets that consisted of balanced meals selected by the individual but devoid of foods containing large amounts of cholesterol. A daily food record kept by each patient was reviewed by a dietitian, and the daily cholesterol intake was estimated at between 100 and $250 \mathrm{mg} /$ day. Analysis of samples of food revealed that cholestanol constitutes $0.1-0.2 \%$ the amount of cholesterol.

The caloric intake was adjusted in each patient to maintain total body weight at a constant level throughout each study. Each individual in whom balance studies were performed received $300 \mathrm{mg} /$ day of chromic oxide as an internal standard to monitor fecal flow (13).

\section{Radioactive compounds and isotope counting}

$\left[1,2-{ }^{3} \mathrm{H}\right]$ Cholestanol was prepared from $\left[1,2-{ }^{8} \mathrm{H}\right]$ cholesterol (New England Nuclear, Boston, Mass.) by catalytic hydrogenation using $\mathrm{PtO}_{2}$ on charcoal as catalyst. The cholestanol was purified by thin-layer chromatography (TLC) on plates coated with silica gel $\mathrm{H}$ that contained $\mathrm{AgNO}_{3}$. The identity and purity of the labeled cholestanol was confirmed by simultaneous counting and gas-liquid chromatography (GLC). The final product had a specific activity of $52 \mu \mathrm{Ci} / \mathrm{mmol}$. [4- ${ }^{14} \mathrm{C}$ ]Cholesterol (sp act $13.4 \mu \mathrm{Ci} / \mathrm{mmol}$ ) was obtained from New England Nuclear. This compound was greater than $99 \%$ pure by TLC on silica gel $\mathrm{H}$ in the system ethyl ether: heptane, $55: 45$ and contained $1.3 \%$ saturated contaminant when examined by $\mathrm{AgNO}_{s}$ TLC.

The labeled sterols, the dosage of radioactivity administered, and the duration of isotopic study are listed in Table II. Patients 1, 2, and 4 were labeled simultaneously with both intravenous $\left[4-{ }^{14} \mathrm{C}\right]$ cholesterol and $\left[1,2-{ }^{3} \mathrm{H}\right]$ cho- lestanol at the beginning of the study. Patients 5-12 received a single intravenous injection of either $\left[4{ }^{14} \mathrm{C}\right]$ cholesterol or $\left[1,2-{ }^{3} \mathrm{H}\right]$ cholestanol. In all cases, the radiosterols were dissolved in $1 \mathrm{ml}$ of ethanol that was then dispersed in $150 \mathrm{ml}$ of physiologic saline; the entire dispersion was immediately infused by vein.

Radioactivity was assayed in a Packard Tri-Carb Scintillation Counter Model 3003 (Packard Instrument Co. Inc., Downers Grove, III.). The purified sterols were dissolved in toluene phosphor (4.2\% Liquiflor, New England Nuclear). Appropriate corrections were made for quenching, crossover, and background as described by Miettinen, Ahrens, and Grundy (14).

\section{Steroid analyses}

Complete stool collections were obtained throughout each study for patients $1-8,13$, and 14 and were combined into 4-day pools. Fecal neutral and acidic steroids were isolated separately, and their masses and specific activities were measured by methods previously developed $(14,15)$. These TLC and GLC procedures permit the essential distinction to be made between plant sterols and cholesterol and between the two families of bacterial conversion products derived from plant sterols and cholesterol during intestinal transit $(5 \beta$, $3 \beta-\mathrm{OH}$, and $5 \beta, 3$-keto compounds).

Corrections for unexplained losses of cholesterol $(12 \%$ in the CTX subjects and $18 \%$ in the controls) during intestinal transit were based upon the recovery of nonlabeled $\beta$-sitosterol inherent in the formula diets (16). Variations in fecal flow and excretion of bile acids were corrected by the recovery of chromic oxide (13).

In order to measure the concentration of cholestanol in plasma or feces, it was necessary to modify the analysis procedure for fecal sterols. A weighed sample of stool $(1 \mathrm{~g})$ or $2 \mathrm{ml}$ of plasma that contained $\left[{ }^{3} \mathrm{H}\right]$ cholestanol either inherent from intravenous labeling or added as an internal 
standard was saponified for $1 \mathrm{~h}$ in $1 \mathrm{~N} \mathrm{NaOH}$. The neutral sterols were extracted with $3-50 \mathrm{ml}$ portions of petroleum ether (bp 60-80). The solvent was evaporated, and the residue redissolved in $10.00 \mathrm{ml}$ of ethyl acetate. $2.00 \mathrm{ml}$ were assayed for radioactivity (pre-TLC), and the remainder was concentrated in the tip of a conical tube and applied to $20 \mathrm{~cm} \times 20 \mathrm{~cm}$ glass plates coated with $0.5-\mathrm{mm}$ thick layers of silica gel $\mathrm{H}$ that contained $\mathrm{AgNO}_{3}(10 \%$ $\mathrm{wt} / \mathrm{wt}$ ). The plates were developed at $4^{\circ} \mathrm{C}$ in chloroform: acetone, $97: 3$; each sterol band was visualized under ultraviolet illumination after the plate was sprayed with a halfsaturated aqueous solution of Rhodamine 6G (Allied Chemical Corp., Industrial Chemicals Div., Morristown, N. J.) and eluted individually with ethyl ether. The solvent was evaporated, and the cholestanol was dissolved in $2.00 \mathrm{ml}$ of ethyl acetate that contained $5 \boldsymbol{\alpha}$-cholestane as an internal standard. $1.00 \mathrm{ml}$ was counted; the remaining cholestanol was converted to its trimethylsilyl (TMS) ether derivative for GiLC by the addition of $20 \mu \mathrm{l}$ of Sil-Prep (Applicd Science Labs, Inc., State College, Pa.). Mass measurements were obtained by GLC on 6-ft glass columns packed with 3\% QF-1 on Gas Chrom Q (100-120 mesh, Applied Science Labs, Inc.). Corrections for analytical losses depended upon the recovery of $\left[{ }^{3} \mathrm{H}\right]$ cholestanol after TLC. Recoveries of $\left[{ }^{3} \mathrm{H}\right]$ cholestanol ranged from 70 to $90 \%$ (average $83 \%$ ) of the radioactivity present before TLC.

Plasma cholesterol and triglyceride concentrations were measured biweekly using a semiautomated method $(17,18)$; on a sample of the same extract used in these determinations ${ }^{14} \mathrm{C}$ radioactivity was assayed, and the specific activity of cholesterol $(\mathrm{dpm} / \mathrm{mg})$ was expressed in a semilogarithmic plot.

\section{Free and esterified sterols in plasma}

The lipids in $2 \mathrm{ml}$ of plasma were extracted in $38 \mathrm{ml}$ of chloroform: methanol, 2:1 after each subject had received $\left[4-{ }^{14} \mathrm{C}\right]$ cholesterol and $\left[1,2-{ }^{3} \mathrm{H}\right]$ cholestanol intravenously. The solvent was evaporated, and the lipid residue was applied on $0.5-\mathrm{mm}$ thick silica gel $\mathrm{H}$ plates; these were developed in petroleum ether:ethyl ether:acetic acid, 85: $15: 0.5$. The sterol bands were detected under ultraviolet illumination after being sprayed with a half-saturated aqueous solution of Rhodamine 6G. In this system the free sterols had an $R_{f}$ value of 0.30 and esterified sterols 0.90 . The bands corresponding to free and esterified cholestero were collected separately, and measurements of sterol esterification were made by determining the proportion of both isotopes in the free and ester fractions.

\section{Lipoprotein isolation}

Lipoproteins were isolated from $12 \mathrm{ml}$ of plasma in the Beckman model L2-65B ultracentrifuge (Beckman Instruments, Inc., Spinco Div., Palo Alto, Calif.) according to the method of Havel, Eder, and Bragdon (19). For separation of low and very low-density lipoproteins (LDL and VLDL), ultracentrifugation was carried out at about $100,000 \mathrm{~g}$ at $15^{\circ} \mathrm{C}$ for $16 \mathrm{~h}$ in a Type 50 titanium rotor; for the separation of high-density lipoproteins (HDL), ultracentrifugation was carried out for $40 \mathrm{~h}$.

\section{Experimental design}

\section{Cholestanol Turnover}

In patients 1, 2, 4, and 9-12, the turnover of cholestanol was determined in the plasma from specific activity-time curves after intravenous labeling with $\left[1-2-^{8} \mathrm{H}\right]$ cholestanol. Assuming a two-pool model (20), calculations were made of the size of each kinetic pool. The excretion of cholestanol in the feces as neutral sterols or bile acids was measured simultaneously in patients 1,2 , and 4 by the isotopic balance method (21) and in patients 3,13 , and 14 by the chromatographic balance technique $(14,15)$ and served as a check of the turnover values calculated by the isotope kinetic method (two-pool model).

\section{Cholesterol Turnover}

In patients 1, 2, and 4-9, cholesterol turnover was determined by mathematical analysis of plasma specific activity decay curves after intravenous labeling with $\left[4-{ }^{14} \mathrm{C}\right]$ cholesterol and at the same time by the sterol balance method. Values for cholesterol production rates and the size of the pool with rapid turnover were calculated from the two-pool model.

\section{Regitintion of Sterol, Biosynthesis in CTX}

Cholestyramine. In patient 3 with CTX, the fecal excretion of cholestanol was measured by the sterol balance method for 20 days before and 24 days after treatment with $10 \mathrm{~g} /$ day cholestyramine. Plasma cholestanol concentrations also were determined by GI.C during both periods.

Clofibrate. In patients 1 and 2 with CTX, measurements of cholesterol and cholestanol turnover were made by the sterol balance technique during a control period (Table II) and after 29 and 21 respective days of treatment with clofibrate, $2 \mathrm{~g} /$ day. The effects of treatment on plasma lipid concentrations and on the log linear portion of the plasma cholesterol specific activity decay curve were ascertained.

\section{RESULTS}

Plasma cholesterol and cholestanol concentrations. Measurements of plasma neutral sterols from three CTX and five control subjects on formula diets containing $40 \%$ cottonseed oil are presented in Table IIIA. Despite the presence of tendon xanthomas, exceedingly low plasma cholesterol levels were found in the CTX subjects $(95 \mathrm{mg} / 100 \mathrm{ml}$ vs. $311 \mathrm{mg} / 100 \mathrm{ml}$ ). However, plasma cholestanol concentrations in the CTX subjects were almost twice those of controls (1.2 mg/ 100 vs. $0.74 \mathrm{mg} / 100 \mathrm{ml}$ ). Therefore, there was six times more cholestanol relative to cholesterol in the CTX plasma than in the controls.

When the CTX subjects ate regular solid-food diets, the plasma concentrations of both cholesterol and cholestanol increased $25 \%$ (Table IIIB). It is not clear whether the rise in plasma neutral sterols was related to the cholesterol and cholestanol content of regular food, to the effect of saturated fats present in solid food, or to some other unidentified factor.

Plasma lipoprotein transport of cholestanol. In order to determine in which lipoprotein fraction cholestanol is transported, plasma specimens from two CTX individuals were fractioned into the three major lipoprotein groups (VLDL, LDL, and HDL) by preparative ultra- 
TABLE III

Concentrations of Cholesterol and Cholestanol in Plasma as Measured by GLC

\begin{tabular}{|c|c|c|c|c|c|c|}
\hline \multirow[b]{2}{*}{ Patients } & \multicolumn{2}{|c|}{$A$ Formula diet $-\mathbf{4 0} \%$ cottonseed oil } & & \multicolumn{3}{|c|}{$B$ Regular food- $40 \%$ saturated fat } \\
\hline & Cholesterol & Cholestanol & & Cholesterol & Cholestanol & \\
\hline & $m g / 100 m l \pm S D$ & $m g / 100 m l \pm S D$ & $\% \ddagger$ & $m g / 100 m l$ & $m g / 100 m l$ & $\% \ddagger$ \\
\hline 1 & $95 \pm 5.3(16)^{*}$ & $0.95 \pm 0.12(16)$ & 1.0 & $129(2)$ & 1.3 & 1.0 \\
\hline 2 & $108 \pm 5.1(14)$ & $1.41 \pm 0.19$ & 1.3 & $117(2)$ & 2.2 & 2.1 \\
\hline 3 & $87 \pm 3.6(16)$ & $1.20 \pm 0.22(16)$ & 1.4 & $127(2)$ & 2.2 & 1.8 \\
\hline $4-8$ & $311 \pm 114$ & $0.74 \pm 0.34$ & 0.23 & & & \\
\hline
\end{tabular}

* Number of determinations.

$\ddagger$ Percentage cholestanol per total sterols.

centrifugation. The absolute quantity of cholesterol and cholestanol was determined by GLC in each lipoprotein fraction and is reported in Table IV. Cholestanol accompanied cholesterol in all three fractions, with the highest amount in the LDL fraction. The ratio of cholesterol to cholestanol was reasonably constant throughout all three lipoprotein fractions in patient 3 but was higher in the VLDL and HDL fraction of patient 1: evidently a plasma lipoprotein that serves specifically for cholestanol transport was not detected by these methods.

The esterification of cholesterol and cholestanol. The rates of esterification of both sterols were studied in patients 1 and 2 with CTX and in patient 4, who was normolipidemic. These subjects were given $\left[4-{ }^{14} \mathrm{C}\right]-$ cholesterol and $\left[1,2-{ }^{8} \mathrm{H}\right]$ cholestanol intravenously, and the distribution of the isotopes between free and ester fractions was determined frequently for the next 13-19 days. The results are shown in Fig. 1. In all patients, $70-75 \%$ of the radioactive cholesterol and cholestanol became esterified after several days. The same percentage of cholesterol was esterified, as determined by quantitative mass assay; thus, the trace quantities of radiosterols were treated by the body identically. However, cholestanol was esterified initially more slowly than cholesterol in patients 2 and 4 , and in the later states of the experiment slightly more cholestanol was esterified than cholesterol. Thus, the synthesis and catabolism of cholestanol esters are similar to cholesterol esters but perhaps have slightly slower rates.

TABLE IV

Cholesterol and Cholestanol in Plasma Lipoproteins

\begin{tabular}{lcc}
\multicolumn{1}{c}{ Patient } & \multicolumn{2}{c}{ Cholesterol/cholestanol } \\
& 1 & 3 \\
\hline & \multicolumn{3}{c}{$m g / m g$} \\
Plasma (per $100 \mathrm{ml}$ ) & $145 / 1.7$ & $151 / 2.4$ \\
VLDL & $28 / 0.22$ & $18 / 0.29$ \\
LDL & $106 / 1.5$ & $113 / 1.9$ \\
HDL & $11 / 0.07$ & $20 / 0.42$ \\
\hline
\end{tabular}

Specific activity of plasma cholestanol. Two patients with CTX (patients 1 and 2) and five control subjects (patients 4, and 9-12) were labeled intravenously with $\left[1,2-{ }^{3} \mathrm{H}\right]$ cholestanol. The specific radioactivities of
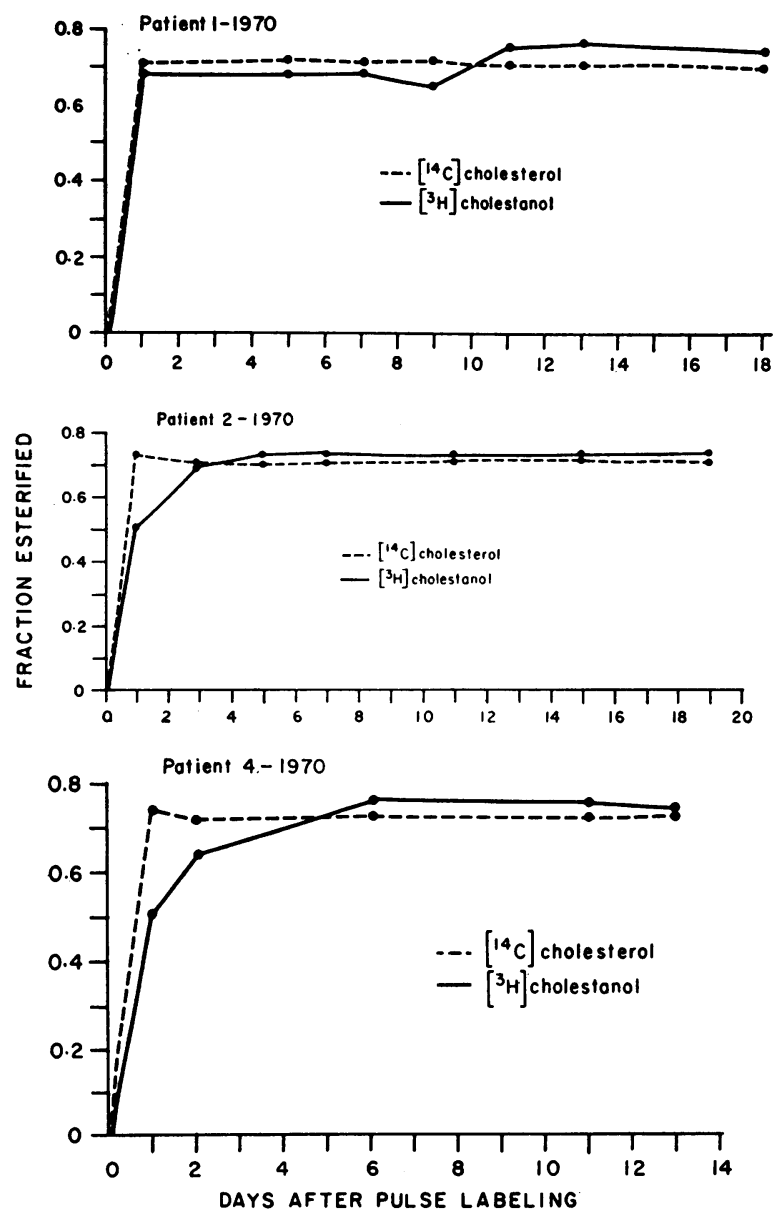

Figure 1 The esterification of $\left[4-{ }^{14} \mathrm{C}\right]$ cholesterol and $[1,2-$ $\left.{ }^{3} \mathrm{H}\right]$ cholestanol. After the intravenous injection of $\left[4-{ }^{14} \mathrm{C}\right]-$ cholesterol and $\left[1,2-{ }^{3} \mathrm{H}\right]$ cholestanol, the relative rates of esterification of both isotopic sterols were compared in patients 1 and 2 , and patient 4 . 


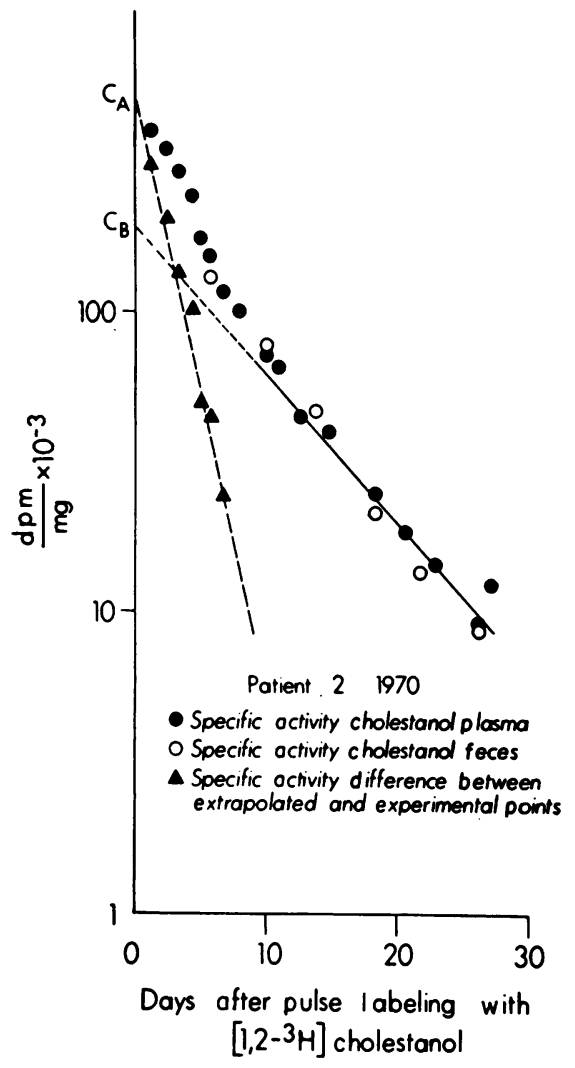

Figure 2 Specific activity-time curve for plasma cholestanol after pulse labeling intravenously with $\left[1,2-{ }^{3} \mathrm{H}\right] \mathrm{cho}-$ lestanol. A two-pool model is suggested by the curve-peeling technique: the difference values (solid triangles obtained by subtracting the points on the extrapolated line from the experimental points) fit a straight line.

plasma cholestanol were measured biweekly for the next 5 wk. Fig. 2 illustrates the specific activity-time curves for $\left[1,2-{ }^{3} \mathrm{H}\right]$ cholestanol in patient 2 (CTX). A twopool model is suggested by the curve-peeling method of Goodman and Noble (22). The specific activities of cholestanol isolated from the feces of this subject also are plotted (open circles) in this figure. They correspond closely with the specific activities of plasma cholestanol, indicating that unlabeled cholestanol was not formed by intestinal bacteria in the colon.

Estimation of cholestanol turnover by the sterol balance method and isotope kinetic method. In two subjects with CTX (patients 1 and 2) and one normolipidemic subject (patient 4) cholestanol turnover was calculated by the isotopic balance technique after $\left[1,2-{ }^{3} \mathrm{H}\right]-$ cholestanol was administered intravenously. The calculation should be valid because the specific activities of fecal cholestanol and presumably of bile acids derived from cholestanol are the same as the specific activity of plasma cholestanol (Fig. 2). Thus, the daily excretion of neutral and acidic steroids that originated from cholestanol can be calculated by dividing the total num- ber of disintegrations per minute of tritium excreted per day by the specific activity of plasma cholestanol obtained 2 days earlier. The values calculated by the method for patients 1,2 , and 4 are presented in Table $\mathrm{V} A$. In addition cholestanol turnover was estimated in four other subjects (patients 3,6,13, and 14) by the chromatographic balance technique. In this procedure, the daily fecal excretion of cholestanol is measured directly by GLC while the daily excretion of acidic steroids derived from cholestanol is estimated by the formula expressed in the footnote in Table $\mathrm{V}$. This equation is based upon the assumption that the ratio of cholesterol to bile acids is identical to the ratio of cholestanol to allo bile acids in the stool. It is valid also because over $97 \%$ of the tritium radioactivity recovered from the thin-layer plates was associated with the cholestanol band and indicated that cholestanol was not modified further by intestinal bacteria.

The values for the excretion of steroids derived from cholestanol are presented in Table VA. The daily fecal

TABLE V

Cholestanol Turnover

\begin{tabular}{|c|c|c|c|c|}
\hline \multirow[b]{2}{*}{ Patient } & \multicolumn{3}{|c|}{$\begin{array}{c}A \\
\text { Cholestanol balance data }\end{array}$} & \multirow[t]{2}{*}{$\begin{array}{c}B \\
\mathrm{PR}_{\mathrm{A}}\end{array}$} \\
\hline & $\begin{array}{l}\text { Neutral } \\
\text { steroids }\end{array}$ & $\begin{array}{l}\text { Acidic } \\
\text { steroids }\end{array}$ & $\begin{array}{c}\text { Total } \\
\text { steroids }\end{array}$ & \\
\hline & \multicolumn{3}{|c|}{$m g / d a y$} & $m g / d a y$ \\
\hline 1 & 36 & 6 & $42^{*}$ & 57 \\
\hline 2 & 38 & 8 & $46^{*}$ & $\begin{array}{l}48 \\
52.5\end{array}$ \\
\hline 3 & 22 & 9 & $\begin{array}{c}31 \ddagger \\
39.7 \pm 8.4 \S\end{array}$ & \\
\hline 4 & 9 & 5 & $14^{*}$ & 8.0 \\
\hline 6 & 7 & 4 & $11 \ddagger$ & \\
\hline 13 & 9 & 2 & $11 \ddagger$ & \\
\hline 14 & 13 & 4 & $17 \ddagger$ & \\
\hline 9 & - & - & - & 6.0 \\
\hline 10 & - & - & - & 18.6 \\
\hline 11 & - & - & - & 18.0 \\
\hline 12 & - & - & $\overline{-}$ & $\begin{array}{c}8.2 \\
11.8 \pm 6.0\end{array}$ \\
\hline
\end{tabular}

* Neutral and acidic steroids determined by isotope balance method.

$\ddagger$ Neutral steroids determined by chromatographic balance method. Acidic steroids were calculated indirectly by assuming that the percentage of bile acids derived from cholestanol was identical to the percentage of bile acids derived from cholesterol. This assumption was proved to be valid in patients 1 and 2 , in whom acidic steroids derived from cholestanol were measured directly by isotopic means. Thus, the acidic steroids in this table were calculated according to the following equation: acidic steroids (from cholestanol) $(\mathrm{mg} /$ day) = neutral steroids (from cholestanol) $(\mathrm{mg} /$ day $) \times$ total acidic steroids $(\mathrm{mg} /$ day $) \div$ endogenous neutral steroids $(\mathrm{mg} /$ day $)$. $\S$ Mean \pm SD. 
TABLE VI

Half-Life of $\left[1,2-{ }^{3} \mathrm{H}\right]$ Cholestanol Exponentials $A$ and $B$ and Sizes of Pool $A$ and Pool B

\begin{tabular}{|c|c|c|c|c|c|c|}
\hline Patient & $\mathrm{C}_{\mathrm{A}} *$ & $\mathrm{C}_{\mathrm{B}} *$ & $\mathrm{t}_{1} \mathrm{~A}$ & $\mathrm{t}_{\mathrm{b}} \mathrm{B}$ & $\mathbf{M}_{\mathbf{A}}$ & $M_{B} \ddagger$ \\
\hline & \multicolumn{2}{|c|}{$d p m / m g$} & \multicolumn{2}{|c|}{ days } & \multicolumn{2}{|c|}{$m g$} \\
\hline 1 & 350,000 & 66,000 & 1.7 & 7.0 & 212 & 212 \\
\hline \multirow[t]{2}{*}{2} & 267,000 & 152,000 & 1.8 & 5.8 & 148 & 67 \\
\hline & & Average & 1.8 & 6.4 & 180 & 140 \\
\hline 4 & 940,000 & 290,000 & 1.6 & 12.0 & 48 & 67 \\
\hline 9 & $1,000,000$ & 870,000 & 2.0 & 5.4 & 31 & 9 \\
\hline 10 & 960,000 & 125,000 & 1.1 & 5.8 & 54 & 57 \\
\hline 11 & 460,000 & 240,000 & 1.0 & 6.0 & 83 & 62 \\
\hline 12 & $3,000,000$ & 620,000 & 1.0 & 6.0 & 22 & 23 \\
\hline $\begin{array}{l}\text { Mean } \\
\pm S D\end{array}$ & & & $1.3 \pm 0.4$ & $7.0 \pm 2.8$ & $48 \pm 23$ & $43 \pm 26$ \\
\hline
\end{tabular}

* Constants which represent intercept of the exponential lines A and B with the $y$ axis when $t=0$.

$\ddagger$ Minimun value.

outputs of cholestanol ranged from 22 to $38 \mathrm{mg} /$ day in the CTX subjects and from 7 to $13 \mathrm{mg} /$ day in the control subjects. The output of acidic steroids derived from cholestanol ranged from 6 to $9 \mathrm{mg} /$ day in the CTX subjects and from 2 to $5 \mathrm{mg} /$ day in the control subjects. Since these individuals had attained the metabolic steady state as manifested by constant body weight and plasma cholestanol concentrations, the sum of the fecal excretion of cholestanol and allo bile acids derived from cholestanol reflects daily turnover.

In two CTX subjects (patients 1 and 2) and five other subjects (patients 4, and 9-12) cholestanol turnover also was estimated through the calculation of production rates $\left(P R_{\mathbf{A}}\right)$ by mathematical analysis of the specific activity decay curves, since these curves conformed to two-pool models. The various kinetic param- eters that underlie these calculations are presented in Table VI, and the production rates are included in Table VB. Cholestanol turnover ( $\left.P R_{\Delta}\right)$ ranged from 6.0 to $18.6 \mathrm{mg} /$ day in the control subjects (mean 11.8 \pm 6.0 ) and were 48 and $57 \mathrm{mg} /$ day (average 52.5) in the two CTX subjects. The difference between the sterol balance method and compartmental analysis of the two-pool model was $16 \%$ and is sufficiently close to support the validity of the turnover values derived by these techniques. Average cholestanol PRA's were 3-4 times greater in the CTX subjects than the controls.

Estimates of cholestanol synthesis. Since cholestanol was not present in the formula diets of patients 1 through 4 or was found in only trace quantities in the regular food diets (patients 9-12), it becomes clear that in the metabolic steady state, daily turnover equals the amount of cholestanol synthesized each day. Therefore, since the control group included both normolipidemic and hyperlipidemic individuals, high cholestanol synthesis is present in CTX.

Calculation of the size of the two miscible pools of cholestanol. From the mathematical analysis of the plasma cholestanol specific activity decay curves, an estimate of the sizes of the rapidly turning-over pool $\left(M_{A}\right)$ and the minimum size of the slowly turning-over pool $\left(\mathrm{M}_{\mathbf{B}}\right)$ of cholestanol can be obtained and are presented in Table VI. $\mathrm{M}_{\mathrm{A}}$ in the two CTX subjects (patients 1 and 2) was $212 \mathrm{mg}$ and $148 \mathrm{mg}$, respectively; both values exceeded the mean value for pool A $\left(M_{A}=48 \pm 23 \mathrm{mg}\right)$ in the control subjects by 4 and 3 times, respectively. $\mathrm{M}_{\mathbf{B}}$ (minimum) for the two CTX subjects was $212 \mathrm{mg}$ and $67 \mathrm{mg}$, and these values were 3 and 1.5 times higher than the mean value for $M_{B}$ $(43 \pm 26 \mathrm{mg})$ calculated in the five control patients. It

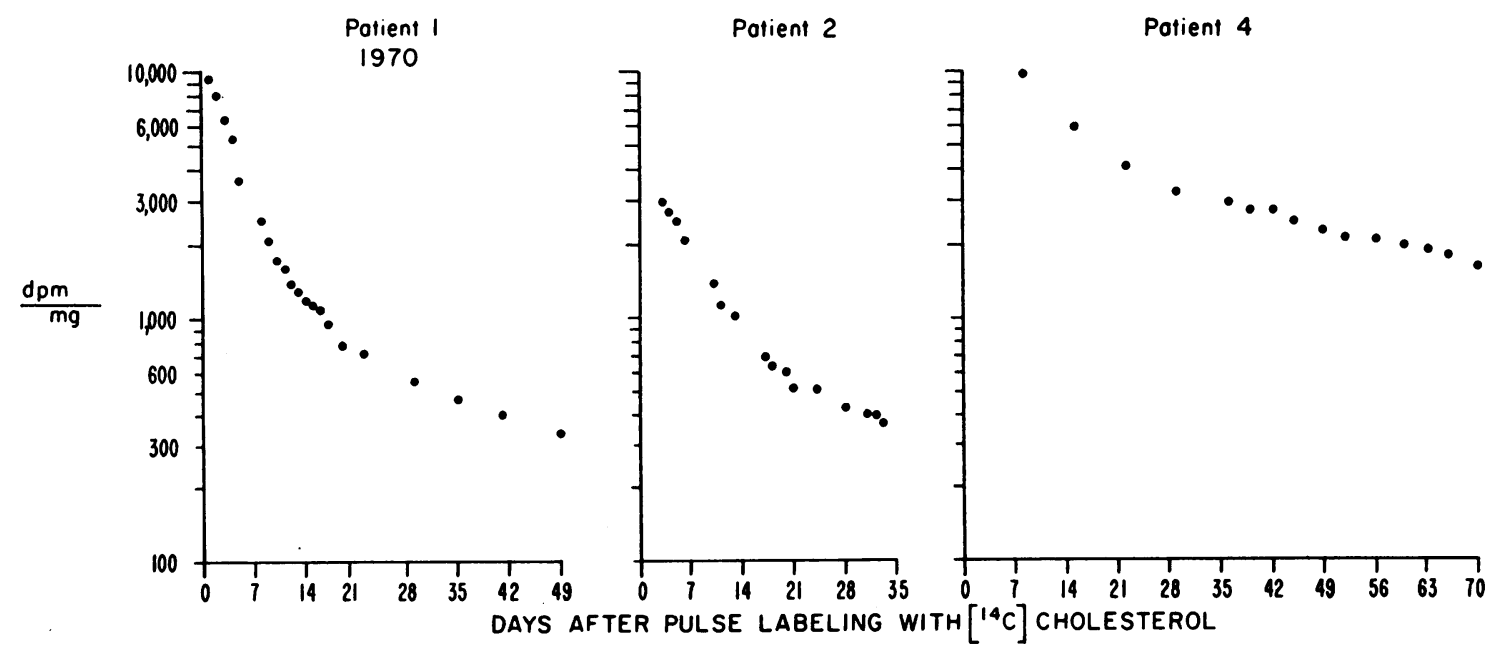

FIGURE 3 Comparison of the plasma specific activity-time curves for $\left[4-{ }^{14} \mathrm{C}\right]$ cholesterol in two subjects with CTX and one normolipidemic control. The exponential decay of $\left[4-{ }^{14} \mathrm{C}\right]-$ cholesterol is very rapid in the CTX subjects. 
TABLE VII

Half-Life of $\left[4-{ }^{14} \mathrm{C}\right]$ Cholesterol Exponential $A$ and Exponential $B$ and Size of Pool A

\begin{tabular}{|c|c|c|c|c|c|}
\hline Patient & $\mathrm{CA}_{\mathrm{A}} *$ & $\mathrm{C}_{\mathrm{B}} *$ & $\mathrm{t}_{3} \mathrm{~A}$ & $\mathrm{t}_{1} \mathrm{~B}$ & $\mathrm{M}_{\mathrm{A}}$ \\
\hline & \multicolumn{2}{|c|}{$d p m / m g$} & \multicolumn{2}{|c|}{ days } & $g$ \\
\hline 1 & 10,000 & 1,070 & 3.1 & 30 & 8.9 \\
\hline \multirow{2}{*}{2} & 4,000 & 1,200 & 5.0 & 20 & 12.0 \\
\hline & & Average & 4.0 & 25 & 10.5 \\
\hline 4 & 9,500 & 3,850 & 6.0 & 68 & 24.9 \\
\hline 5 & 1,850 & 890 & 8.0 & 99 & 21.7 \\
\hline 6 & 4,500 & 3,000 & 4.0 & 42 & 39.6 \\
\hline 7 & 11,000 & 2,800 & 6.0 & 91 & 21.5 \\
\hline 8 & 4,000 & 2,100 & 5.8 & 38 & 48.7 \\
\hline $\begin{array}{l}\text { Mean } \\
\text { \%SD }\end{array}$ & & & $5.8 \pm 1.4$ & $67.6 \pm 27.6$ & $31.3 \pm 12.3$ \\
\hline
\end{tabular}

* Constants which represent of the intercepts of exponential line $A$ and $B$ with $\mathrm{y}$ axis when $\mathrm{t}=\mathbf{0}$.

should be emphasized that the calculations of $\mathrm{M}_{\mathbf{B}}$ are minimum values based on the assumption that no appreciable synthesis or removal of cholestanol occurs in the tissues that comprise this pool. In addition, specific activities were measured for only $4-5 \mathrm{wk}$, and although the rate of decay for $\left[{ }^{3} \mathrm{H}\right]$ cholestanol was very rapid [sp act of $\left[{ }^{3} \mathrm{H}\right]$ cholestanol on day 36 was $1 / 300$ of the initial sp act] a third exponential might might have appeared if measurements were continued longer. Consequently, the calculated values for $\mathrm{M}_{\mathrm{B}}$ represent very rough estimates, and correct values may be much larger. Despite these qualifications the data show expanded body pools of cholestanol in the CTX subjects and are in accord with previous tissue measurements that also showed greatly increased tissue concentrations of cholestanol (6).
Estimation of cholesterol turnover by two independent methods. In two patients with CTX (patients 1 and 2) and five control subjects (patients 4 through 8 ) cholesterol turnover was determined by analysis of plasma specific activity-time curves after intravenous labeling with $\left[4{ }^{14} \mathrm{C}\right]$ cholesterol. Cholesterol specific activities were measured for 5-10 wk (Table II) and in all cases conformed to two-pool models (22). The curves for the two CTX subjects and one normolipidemic subject are shown in Fig. 3. Kinetic values for all subjects are listed in Table VII. In the CTX subjects, $\left[{ }^{14} \mathrm{C}\right]$ cholesterol decayed very rapidly as compared with the control subjects; the respective half-lives of $\left[{ }^{14} \mathrm{C}\right]-$ cholesterol exponentials $\mathrm{A}$ and $\mathrm{B}$ were $31 \%$ and $63 \%$ shorter than the mean control values. Cholesterol $\mathrm{PR}_{\mathrm{A}}$ for the two CTX subjects (Table VIII $A$ ) were $1085 \mathrm{mg} /$ day and $987 \mathrm{mg} /$ day, respectively, whereas the mean value in the control subjects was $736 \mathrm{mg} /$ day. Since the CTX subjects were small, the differences were even larger when the turnover rates were expressed as milligram per kilogram per day: the average value for the two CTX subjects was $18.2 \mathrm{mg} / \mathrm{kg} / \mathrm{day}$ as compared with a mean value of $11.1 \pm 3.6 \mathrm{mg} / \mathrm{kg} / \mathrm{day}$ in the controls. Since diets were low in cholesterol, turnover is equivalent to endogenous synthesis.

Cholesterol turnover was measured simultaneously by the sterol balance method. The results are presented in Table VIIIB. For the control subjects, the correspondence of turnover rates between the sterol balance and isotope kinetic methods was quite good; $674 \pm 187$ $\mathrm{mg} /$ day vs. $736 \pm 261$. However, in the two CTX subjects it was not possible to measure accurately the output of endogenous neutral sterols by the chromato-

TABLE VIII

Cholesterol Turnoier

\begin{tabular}{|c|c|c|c|c|c|c|c|}
\hline \multirow[b]{3}{*}{ Patient } & \multirow{2}{*}{\multicolumn{2}{|c|}{$A$}} & \multicolumn{3}{|c|}{$\begin{array}{c}B \\
\text { Sterol balance method }\end{array}$} & \multirow{3}{*}{$=$} & \\
\hline & & & \multicolumn{2}{|c|}{ Endogenous neutral sterols } & \multirow{2}{*}{$\frac{\text { Bile acids }}{\text { Chromatographic }}$} & & \\
\hline & \multicolumn{2}{|c|}{$\mathrm{PR}_{\mathrm{A}}$} & Chromatographic & Isotopic & & & \\
\hline & $m g / d a y$ & $\mathrm{mg} / \mathrm{kg} / \mathrm{day}$ & \multicolumn{2}{|c|}{$m g / d a y$} & $m g / d a y$ & $m g / d a y$ & $m g / k g / d a y$ \\
\hline 1 & 1085 & 18.4 & - & $788 \pm 257(5)^{*}$ & $136 \pm 46$ & 924 & 16.0 \\
\hline 2 & 987 & 18.0 & 一 & $588 \pm 81(5)$ & $93 \pm 27$ & 681 & 12.4 \\
\hline Average & 1036 & 18.2 & & 688 & 115 & 803 & 14.2 \\
\hline 4 & 665 & 11.3 & $529 \pm 121$ & - & $306 \pm 73$ & 834 & 11.4 \\
\hline 5 & 396 & 7.3 & $243 \pm 21$ & - & $116 \pm 42$ & 359 & 6.6 \\
\hline 6 & 922 & 11.4 & $474 \pm 39$ & - & $234 \pm 58$ & 708 & 8.7 \\
\hline 7 & 634 & 8.7 & $463 \pm 51$ & - & $210 \pm 48$ & 674 & 9.2 \\
\hline $8 \ddagger$ & 1062 & 16.6 & $590 \pm 69(8)$ & - & $205 \pm 35$ & 795 & 12.4 \\
\hline \multicolumn{2}{|c|}{ Mean \pm SD $736 \pm 261$} & $11.1 \pm 3.6$ & $459 \pm 131$ & & $214 \pm 68$ & $674 \pm 187$ & $9.7 \pm 2.3$ \\
\hline
\end{tabular}

* ( ), no. of observations.

$\ddagger 12 \%$ over ideal weight. 
graphic method because these individuals excrete large amounts of cholesterol precursors in the stool. These intermediates in the cholesterol biosynthetic pathway are structurally similar to cholesterol, and their GLC peaks overlap with those of cholesterol, dietary plant sterols, and their respective bacterial conversion products. However, since these subjects had been labeled intravenously with radioactive cholesterol, neutral sterols of cholesterol origin were determined isotopically. This technique measures the excretion of radioactive cholesterol and its neutral steroid transformation products but not cholesterol precursors or dietary plant sterols, which are not radioactive. The bile acids were determined by the usual chromatographic method, and the results are summarized in Table VIII.

As was the case for compartmental analyses of the two-pool model, the total excretion of steroids derived from cholesterol was quite high in patient 1 but did not differ from the control values for patient 2 . However, when total steroid outputs were expressed again as $\mathrm{mg} / \mathrm{kg} /$ day to compensate for variation in body weight, cholesterol turnover was 39\% higher in patient 1 and $22 \%$ higher in patient 2 than the mean value in the control subjects. In interpreting these results it is important to stress that the control patients were a heterogeneous group not only in terms of their plasma lipoprotein abnormalities but also in body build. Patient 8 was obviously obese ( $18 \%$ over ideal weight), and we believe her augmented cholesterol synthesis was related to her excess body weight (23). Furthermore, although cholesterol synthesis was high in the CTX subjects, it would not be surprising to find similar rates in individuals with other lipid disorders.

The average difference between the sterol balance and isotope kinetic methods in the two CTX subjects was $22 \%$, while in all seven patients it was $13.5 \%$. These data thus show the expected variation found in two previous studies where the mean difference between the methods in ten subjects was $15 \%$ (24), and in four subjects was $8 \%(25)$. The comparability of turnover values by these two independent techniques supports the premises on which the methods are based and adds confidence in the validity of the turnover results.

Despite the high flow of total fecal steroids, bile acid outputs were remarkably small in the CTX subjects (Table VIII). These values were only about one-half as large as the bile acid outputs in the control subjects: $115 \mathrm{mg} /$ day vs. $214 \mathrm{mg} /$ day. Since the fecal loss of bile acid should equal daily synthesis, bile acid production in the CTX subjects was quite low. Thus, the proportion of fecal endogenous steroids excreted as neutral steroids was elevated in the CTX subjects and was reflected by an increase in the ratio of cholesterol to bile acids in the feces: 6 to 1 in the CTX subjects but only 2.5 to 1 in the controls. Perhaps the increase in fecal neutral sterols represents cholesterol that could not be transformed into bile acids.

Estimation of the miscible cholesterol pools. Assuming a two-pool model, compartmental analysis of the specific activity decay curves of cholesterol provides a reasonable estimate of the size of the rapidly turning over pool of cholesterol, $\mathrm{M}_{\mathbf{A}}(26,27)$. The calculations were made by the formula given by Goodman and Noble (22), and the results are listed in Table VII. In the control subjects, $M_{A}$ ranged from $21.5 \mathrm{~g}$ to 48.7 $\mathrm{g}$ (mean $31.3 \pm 12.3 \mathrm{~g}$ ), these values agree well with previous estimates of the size of this pool in other hyperlipidemic and normal individuals $(24,25)$. In contrast, $\mathrm{M}_{\mathrm{A}}$ in the CTX subjects measured only 8.9 $\mathrm{g}$ and $12.0 \mathrm{~g}$ respectively and were much smaller than the control values.

Minimum values of the size of the slowly turning over pool of cholesterol $\left(\mathrm{M}_{\mathbf{B}}\right)$ were also computed. The average size of $\mathrm{M}_{\mathbf{B}}$ (minimum) in the two CTX subjects was $27.4 \mathrm{~g}$ as compared with a much higher mean size of $42.9 \pm 11.2 \mathrm{~g}$ in the five control subjects. Unfortunately, the accuracy of this calculation is poor because of the short duration of the isotopic experiments $(26,27)$ and also because of the possibility that some cholesterol was synthesized or degraded in the tissues of this pool. Despite these qualifications, it is still surprising that both body miscible pools $\left(M_{A}+M_{B}\right.$ minimum) of cholesterol were small in the CTX subjects, especially in view of the large tendon xanthomata and tissue sterol deposits that characterize these individuals (6).

Effects of cholestyramine. The effects of interrupting the enterohepatic circulation of bile acids on plasma cholestanol concentrations and the fecal excretion of cholestanol are presented in Fig. 4. During treatment with $10 \mathrm{~g}$ of cholestyramine/day, fecal cholestanol output rose from an average of 22 to $46 \mathrm{mg} /$ day and allo bile acid ${ }^{3}$ excretion increased from an average of 9 to $22 \mathrm{mg} /$ day. Plasma cholestanol levels also increased from a mean of $1.4 \mathrm{mg} / 100 \mathrm{ml}$ to almost $4 \mathrm{mg} / 100 \mathrm{ml}$.

Effect of clofibrate on sterol metabolism in Patients with CTX. After a control period, patients 1 and 2 were given $2 \mathrm{~g}$ of clofibrate each day for 29 and 21 days, respectively. In the control period both patients had received $\left[4-{ }^{14} \mathrm{C}\right]$ cholesterol, and determinations of plasma cholesterol specific activity were made during the entire study. Throughout both periods measure-

\footnotetext{
${ }^{3}$ Allo bile acids were estimated indirectly: the percentage of allocholic acid in the biliary bile acids were determined by GLC. This fraction was multiplied by the mass of acidic steroids excreted in the stool each day. Only allocholic acid was considered since neither allochenodeoxycholic acid nor allodeoxycholic acid was detected in the bile.
} 

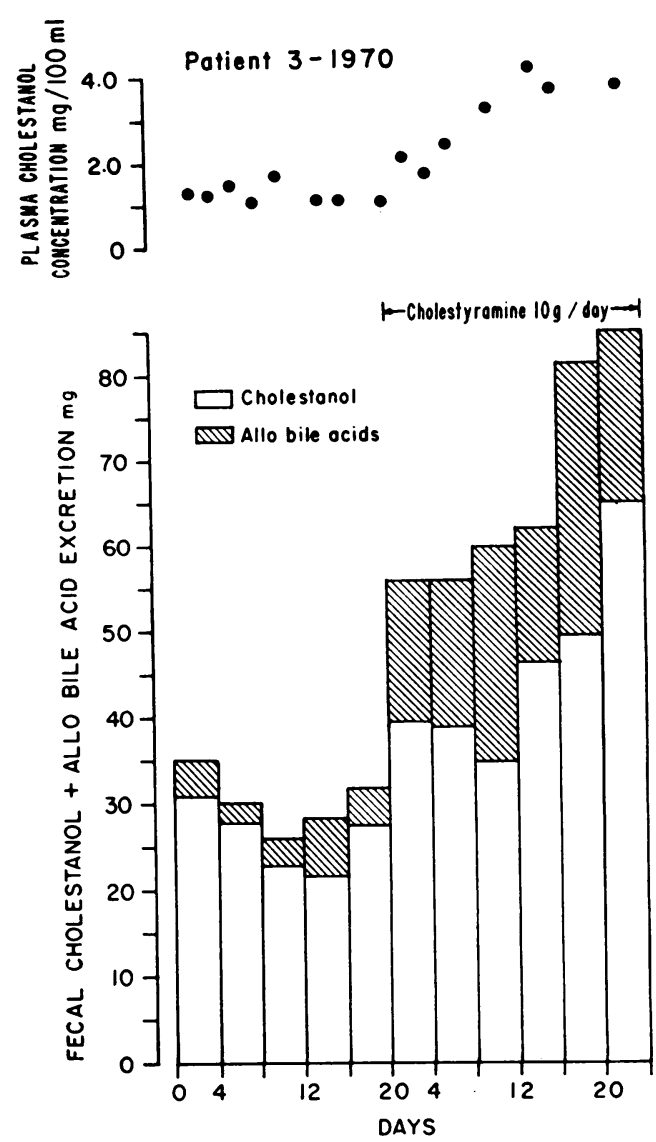

FIGURE 4 The effect of cholestyramine on plasma cholestanol levels and the fecal output of cholestanol and allo bile acids. Greatly augmented fecal outputs of both cholestanol and allo bile acids were noted and were associated with a marked rise in plasma cholestanol concentrations during therapy.

ments of cholesterol and cholestanol balance were made by the isotopic balance technique.

The effects of clofibrate on the specific activity decay curves of plasma cholesterol are illustrated in Fig. 5. In the control period, the decay in plasma specific activity was rapid in both patients. However, when clofibrate was introduced, there was an abrupt decrease in the rate of decay. A similar change has been noted previously in many patients with various types of hyperlipemia (28). The effects of clofibrate on plasma sterol concentrations and sterol balance are illustrated in Fig. 6. During this treatment, plasma cholesterol concentrations did not change significantly. Similarly little effect was noted on total sterol balance, although bile acid outputs increased in both subjects.

In contrast, much greater effects were observed on cholestanol metabolism during clofibrate treatment; plasma cholestanol concentrations were reduced 56\% in patient 1 and $31 \%$ in patient 2 . The changes in

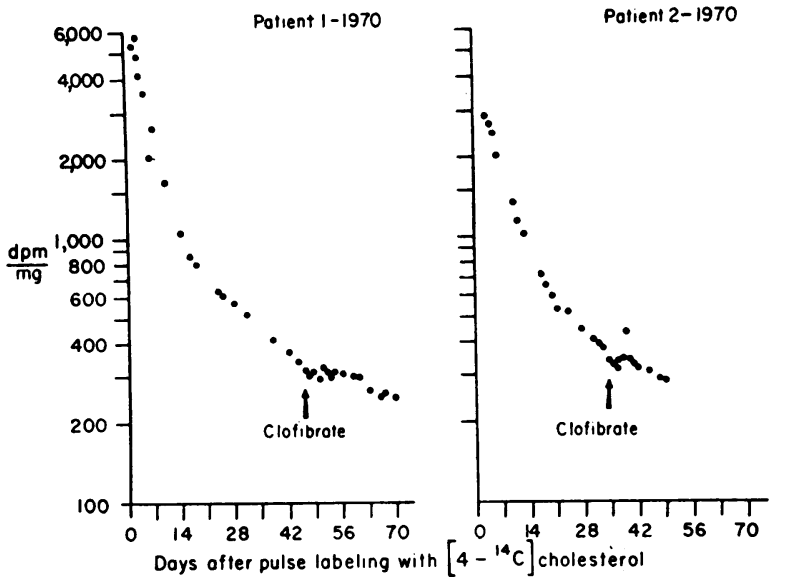

FIGURE 5 The effect of clofibrate on the specific-activity decay of plasma $\left[4-{ }^{14} \mathrm{C}\right]$ cholesterol. The administration of clofibrate was associated with an abrupt upward deflection in the slope of the decay curves.

plasma cholestanol were associated with a $44 \%$ reduction in fecal cholestanol output in patient 1 and a 35\% decrease in fecal cholestanol output in patient 2. Both changes were highly significant statistically $(P<$ $0.001)$. Since there was no cholestanol present in the diet, the reduction of cholestanol plasma concentrations and fecal excretion might have resulted from suppression of synthesis.

\section{DISCUSSION}

The major aim of this investigation was to examine by the isotope kinetic and sterol balance methods the metabolism of cholestanol and cholesterol in CTX patients with the objective of defining the biochemical $\operatorname{defect}(\mathrm{s})$ in this disease.

\section{Cholestanol metabolism}

Turnozer of cholestanol. According to the theory of the two-pool model, the daily cholestanol PRA should equal the amount of new cholestanol that enters the more rapidly exchangeable pool $\left(\mathrm{M}_{\mathrm{A}}\right)$ exclusive of recirculated cholestanol (22). Analysis of the decay curve of plasma specific activity after pulse labeling indicated that the turnover of cholestanol conformed to a twopool model (Fig. 1). Mathematical analysis of the specific activity decay curves provided estimates of the daily $\mathrm{PR}_{\mathrm{A}}$. In seven studies turnover calculated in this manner was approximately fourfold greater in two CTX subjects than in control subjects. Values for the total daily excretion of cholestanol derived by the isotopic balance method corresponded favorably with values for turnover calculated by compartmental analysis of the two-pool model (difference 16\%). A similar comparability also has been reported by these two inde- 


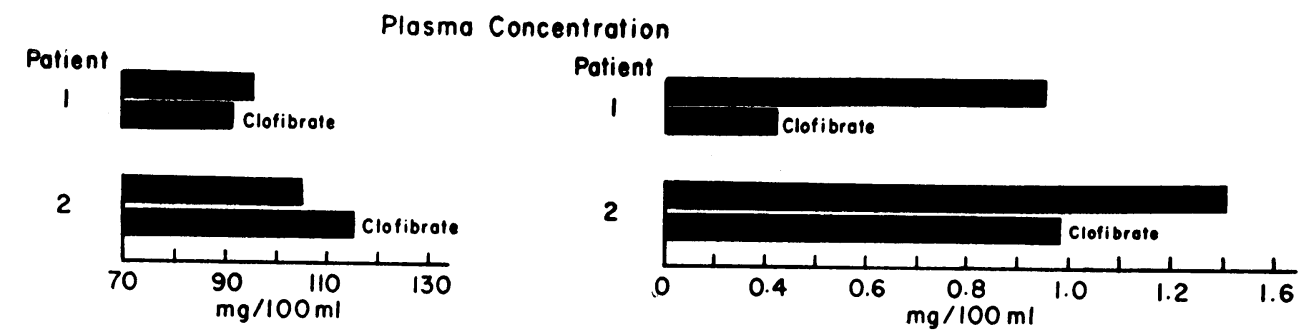

Fecal Steroids
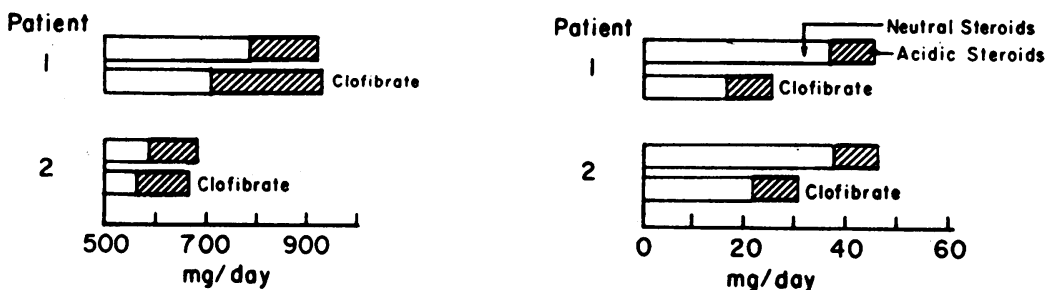

2

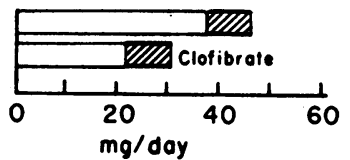

FIGURE 6 The effect of clofibrate on plasma neutral sterols and fecal steroid outputs in two subjects with CTX. The administration of clofibrate resulted in markedly decreased cholestanol plasma concentrations and fecal outputs, but produced no change in either cholesterol plasma concentrations or fecal excretions.

pendent methods for the turnover of the plant sterol $\beta$-sitosterol in man (25). It is of interest that although this sterol enters the body by a different route [ $\beta$-sitosterol is absorbed from the diet, while cholestanol is produced within the body (see below)], the plasma specific activity decay curves of both sterols conform to a two-pool model. Perhaps a similarity of lipoprotein transport (Table IV) accounts for the comparability.

Evidence for endogenous cholestanol synthesis. Two additional lines of evidence were presented in this paper showing that cholestanol was formed endogenously in both CTX and control subjects. (a) In all four patients who were fed cholestanol-free diets (patients 1-4) constant plasma levels were attained (Table III). Since the diets were free of cholestanol new synthesis served as the major source of plasma cholestanol. (b) After $\left[{ }^{3} \mathrm{H}\right]$ cholestanol was given intravenously, the specific activity of plasma cholestanol equaled the specific activity of fecal cholestanol (Fig. 2). This observation ruled out the possibility that cholestanol arose through the reduction of cholesterol by intestinal bacteria. If this path had been followed, the specific activity of fecal cholestanol would have been lower than plasma due to a dilution of fecal cholestanol by that produced from bacteria. These observations supplement our previous study concerning the biosynthetic pathway for cholestanol. Although the precise pathway was not completely elucidated, cholestanol was shown to have originated' endogenously from cholesterol (29). Two experiments were presented: $(a)$ the direct trans- formation of $\left[4-{ }^{14} \mathrm{C}\right]$ cholesterol into $\left[{ }^{14} \mathrm{C}\right]$ cholestanol was observed, proving that cholestanol, like bile acids and steroid hormones, is a degradation product of cholesterol. (b) Cholestanol biosynthesized from a mixture of $\left[2-{ }^{14} \mathrm{C}\right]$ mevalonate and stereospecifically labeled $[3 R$, $\left.4 R-4^{3} \mathrm{H}\right]$ mevalonate exhibited the same isotopic ratio $\left({ }^{3} \mathrm{H} /{ }^{14} \mathrm{C}\right)$ as found in cholesterol.

It is presently believed that cholesterol is transformed into cholestanol via a ketonic intermediate. This conclusion was based upon the study of Rosenfeld, Zumoff, and Hellman, who reported that cholestanol isolated from a diabetic man after $\left[3 \alpha-{ }^{3} \mathrm{H}, 4-{ }^{14} \mathrm{C}\right]$ cholesterol was administered intravenously contained a much lower ${ }^{3} \mathrm{H} /{ }^{14} \mathrm{C}$ ratio than originally present in cholesterol (30). The loss of ${ }^{3} \mathrm{H}$ radioactivity indicated that the $3 \alpha-{ }^{3} \mathrm{H}$ had been removed during the transformation of cholesterol into cholestanol, presumably by the oxidation of the $3 \beta$ $\mathrm{OH}$ group to a ketone. Although this key intermediate has not been identified, it has been suggested that cholest-4-en-3-one is the precursor (31).

Turnover equals synthesis. Since diets were essentially free of cholestanol, all of our evidence leads us to conclude that cholestanol was synthesized endogenously from cholesterol. Therefore, the daily turnover of cholestanol, whether calculated by the analysis of the two-pool model or measured by the isotopic balance method, must equal daily synthesis. Thus, cholestanol production in the CTX patients was substantially greater than in the control patients.

Cholestanol pool size. We have previously shown by 
direct tissue measurements that tissue cholestanol concentrations and the percentage of cholestanol in total sterols were greatly increased in the CTX subjects as compared with normal (6). This observation has received additional support by the calculations of cholestanol pool sizes from the analysis of the specific activity decay curves. Both CTX subjects had much larger pools of miscible cholestanol than the control subjects. These findings are in agreement with the concept of a systemic cholestanolosis in this disease. Indeed, the diagnosis of this condition can be established by finding elevated tissue or plasma cholestanol levels even in absence of the typical clinical syndrome (6).

\section{Cholesterol metabolism}

Cholesterol synthesis. The measurements of cholesterol PRA by analysis of the two-pool model provided a quantitative means of assessing cholesterol synthesis in these subjects. Since the diets contained very little cholesterol we have considered the absorption of exogenous cholesterol to be nil. Thus the PRA, which includes synthesis plus absorption, approximated only daily synthesis in these subjects. When the values were normalized for body weight to compensate for differences in size of the subjects, cholesterol synthesis was almost twice as great in the CTX subjects as in the controls. Simultaneous measurements of cholesterol synthesis obtained by the sterol balance method were somewhat lower than the values calculated by the isotope kinetic technique. A number of reasons have been proposed recently to explain this discrepancy. Samuel and Lieberman have examined cholesterol specific activity decay curves in 17 patients where the measurements were carried out for over $50 \mathrm{wk}$ (27). In 12 of the 17 patients a third exponential appeared after $25 \mathrm{wk}$, and probably reflected a third kinetic pool of more slowly exchangeable cholesterol. Samuel, Perl, Holtzman, Rochman, and Lieberman in another study also noted that if xanthomata were present, the specific activity of xanthoma cholesterol differed widely from plasma cholesterol specific activity and indicated that this cholesterol might constitute a fourth more slowly exchangeable kinetic pool (32) and might be a problem in patients with xanthomatosis. When the various kinetic parameters were derived by input-output analysis and compared with similar values obtained from analysis of 10-12-wk segments of the same curves, important quantitative differences between the short-term and long-term kinetic values were noted. The cholesterol $\mathrm{PR}_{\mathrm{A}}$ derived from the 50-wk curves were 8-14\% lower than for the 10-12-wk curve. $\mathrm{M}_{\mathrm{A}}$ did not differ between the methods, but $\mathrm{M}_{\mathbf{B}}$ minimum was almost $40 \%$ higher when derived from the long-term decay curves. A similar criticism of the two-pool model for calculating cholesterol turnover has been presented by Goodman, Noble, and
Dell, who analyzed cholesterol-specific radioactivity-time curves in six subjects for 32-41 wk (26). Although visual analysis of all curves suggest a two-pool model, computer analysis revealed the long-term curves best fit a three-pool model. Calculation of cholesterol PRA were 8-9\% lower when derived from the three-pool model. Pool A was essentially unchanged, but minimum or maximum values for $M_{B}$ differed appreciably between the two kinetic methods. Therefore, if PRs was reduced $8-14 \%$ in our seven subjects (Patients 1, 2, and 4-8), much closed correspondence with the turnover values derived by the sterol balance method would be observed. Finally, it should be noted that another potential source of error concerns the loss of cholesterol from the skin. Bhattacharyya, Conner, and Spector reported that between 10 to $15 \%$ of the daily turnover of cholesterol was lost through the skin (33). Therefore, the fecal outputs of cholesterol and bile acid would have to be corrected upward by the loss of cholesterol through the epidermis. Despite these qualifications, average cholesterol synthesis $(\mathrm{mg} / \mathrm{kg} /$ day) in the CTX subjects was $39 \%$ higher if determined by the isotope kinetic method and $32 \%$ higher if determined by the sterol balance method than in the control patients. These quantitative measurements are supported by two additional observations. First, substantial quantities of lanosterol, dihydrolanosterol, and $\Delta^{7}$-cholestenol have been detected in the bile of these subjects (6). These sterols are intermediates in cholesterol biosynthesis, and we suspect their secretion in the bile signifies active hepatic cholesterol synthesis. Second, the hepatic level of $\beta$ hydroxy, $\beta$-methylglutaryl $\mathrm{CoA}$ reductase, the rate-determining enzyme of cholesterol biosynthesis, was 3-4 times greater in patient 2 (CTX) than 16 other individuals who were either normal or manifested lipid abnormalities." This hepatic microsomal enzyme controls the rate of formation of mevalonic acid from $\beta$ hydroxy, $\beta$-methylglutaryl CoA, which is the first totally committed step in the cholesterol biosynthetic pathway. The combination of these independent lines of evidence leads us to conclude that cholesterol synthesis is elevated in CTX.

Bile acid turnover. In order to maintain a constant enterohepatic pool of bile acids, new production must equal the fecal loss of bile acids. Determination of fecal acidic steroid excretion must then equal hepatic bile acid synthesis. In the CTX subjects, the average daily excretion of fecal acidic steroids was $46 \%$ less than in the controls (Table VIII). This suggested that bile acid formation was extremely low in this disease.

\footnotetext{
¿Nicolau, G., S. Shefer, G. Salen, and E. H. Mosbach. 1973. Determination of hepatic 3-hydroxy-3-methylglutaryl-CoA reductase activity in man. Submitted for publication.
} 
Previously, we reported that biliary bile acid composition was qualitatively abnormal in the CTX subjects and was characterized by an extremely low proportion of chenodeoxycholic acid (6). The low fecal bile acid excretion probably eliminated the possibility that selective intestinal malabsorption of chenodeoxycholic acid was responsible for the deficiency of this bile acid in the bile. Recently, Garbutt and Kenny reported that the administration of cholestyramine to normal individuals reduced the proportion of chenodeoxycholic acid and concomitantly increased cholic acid in the bile (34). However, this study did not distinguish the mechanism: either preferential intestinal loss of chenodeoxycholic acid or enhanced hepatic cholic acid synthesis could have occurred. However, in the CTX subjects cholestyramine should aggravate the deficiency of chenodeoxycholic acid in the bile. It is, therefore, noteworthy that cholestanol plasma levels and fecal outputs rose during this therapy.

Although clofibrate apparently interferes with cholestanol synthesis, the replacement of chenodeoxycholic acid in the gut seems a more logical therapy. As shown in a preliminary communication, the administration of $750 \mathrm{mg} /$ day of this primary bile acid apparently resulted in a marked reduction in the synthesis of both cholesterol and cholestanol (35). Although noticeable improvement in the clinical syndrome may require prolonged treatment, the apparent normalization of neutral sterol production with chenodeoxycholic acid is encouraging.

To summarize, the findings of this report suggest the overactive cholesterol and cholestanol synthesis were associated with impaired bile acid production in the CTX individuals. It is tempting to speculate that hyperactive neutral sterol synthesis occurred in response to a deficiency of bile acids in the enterohepatic circulation.

\section{ACKNOWLEDGMENTS}

We are grateful to Dr. E. H. Ahrens, Jr., in whose laboratory a portion of these studies was completed and to Drs. Thomas W. Meriwether, III, of Memphis, Tenn., and William Harlan of Birmingham, Ala., for the referral of the patients. Mrs. Norma Deering and Miss Rubell Smith provided excellent technical assistance.

This work was supported by U. S. Public Health Service Research Grant HE-06222 from the National Heart and Lung Institute, U. S. Public Health Service Grant FR00102 from the General Clinical Research Centers Branch of the Division of Research Facilities and Resources, U. S. Public Health Service Grant NS-10092 from the National Institute of Neurological Diseases and Stroke, and National Science Foundation Grant GB-31919X.

\section{REFERENCES}

1. Harlan, W. R., J. B. Graham, and E. H. Estes. 1966. Familial hypercholesterolemia: a genetic and metabolic study. Medicine (Baltimore). 45: 77.

$$
\text { G. Salen and S. M. Grundy }
$$

2. Piper, J., and L. Orrild. 1956. Essential familial hypercholesterolemia and xanthomatosis. Follow-up study of twelve Danish families. Am. J. Med. 21: 34.

3. Frederickson, D. S., R. I. Levy, and R. S. Lees. 1967. Fat transport in lipoproteins: an integrated approach to mechanisms and disorders. N. Engl. J. Med. 276: 34, 94, 148, 215, 273.

4. Van Bogaert, L., H. J. Scherer, and E. Epstein. 1937. Une forme célébrale de cholestérinose géneralisée. Massoon et Cie., Paris.

5. Schimschock, J. R., E. C. Alvord, Jr., and P. D. Swanson. 1968. Cerebrotendinous xanthomatosis: clinical and pathologic studies. Arch. Neurol. 18: 688.

6. Salen, G. 1971. Cholestanol deposition in cerebrotendinous xanthomatosis: a possible mechanism. Ann. Intern. Med. $75: 843$.

7. Menkes, J. H., J. R. Schimschock, and P. D. Swanson. 1968. Cerebrotendinous xanthomaosis: the storage of cholestanol within the nervous system. Arch. Ncurol. $19: 47$.

8. Mosbach, E. H., J. Blum, E. Arroyo, and S. Milch. 1963. A new method for the determination of dihydrocholesterol in tissue. Anal. Biochem. 5: 158.

9. Statistics Bulletin-Metropolitan Life Insurance Co., New York. 1959. November, December. 40.

10. Hughes, J. D., and T. W. Meriwether, III. 1971. Familial pseudohypertrophy of tendo-Achillis with multisystem disease. South. Med. J. 64: 311 .

11. Harlan, W. R., Jr., and W. J. S. Still. 1968. Heriditary tendinous and tuberous xanthomatosis without hyperlipemia. A new lipid storage disorder. N. Engl. J. Med. 278: 416.

12. Ahrens, E. H., Jr. 1970. The use of liquid formula diets in metabolic studies: 15 years' experience. $A d v$. Metab. Disord. 4: 297.

13. Davignon, J., W. J. Simmonds, and E. H. Ahrens, Jr. 1968. Usefulness of chromic oxide as an internal standard for balance studies in formula-fed patients and for assessment of caloric function. J. Clin. Invest. 47: 127.

14. Miettinen, T. M., E. H. Ahrens, Jr., and S. M. Grundy. 1965. Quantitative isolation and gas-liquid chromatographic analysis of total dietary and fecal neutral steroids. J. Lipid Res. 6: 411.

15. Grundy, S. M., E. H. Ahrens, Jr., and T. A. Miettinen. 1965. Quantitative isolation and gas-liquid chromatographic analysis of total fecal bile acids. J. Lipid Res. 6: 397 .

16. Grundy, S. M., E. H. Ahrens, Jr., and G. Salen. 1968. Dietary $\beta$-sitosterol as an internal standard to correct for cholesterol losses in sterol balance studies. J. Lipid Res. 9 : 374.

17. Block, W. D., K. J. Jarret, and J. B. Levine. 1965. Use of a single color reagent to improve the automated determination of serum total cholesterol. Automat. Anal. Chem. Tech Symp. 345.

18. Kessler, G., and H. Laderer. 1965. Fluorometric measurement of triglycerides. Automat Anal. Chem. Tech. Symp. 341.

19. Havel, R. J., H. A. Eder, and J. H. Bragdon. 1955. The distribution and chemical composition of ultracentrifugally separated lipoproteins in human serum. J. Clin. Invest. $34: 1345$.

20. Gurpide, E., J. Mann, and E. Sandberg. 1964. Determination of kinetic parameters in a two-pool system 
by administration of one or more tracers. Biochcmistry. 3: 1250 .

21. Hellman, L., R. S. Rosenfeld, W. Insull, Jr., and E. H. Ahrens, Jr. 1957. Intestinal excretion of cholesterol: a mechanism for regulation of plasma levels. J. Clin. Invest. 36: 898 (Abstr.)

22. Goodman, DeW. S., and R. P. Noble. 1968. Turnover of plasma cholesterol in man. J. Clin. Invest. 47: 231.

23. Nestel, P. J., H. M. Whyte, and DeW. S. Goodman. 1969. Distribution and turnover of cholesterol in humans. J. Clin. Invest. 48: 982.

24. Grundy, S. M., and E. H. Ahrens, Jr. 1969. Measurements of cholesterol turnover, synthesis, and absorption in man carried out by isotope kinetic and sterol balance methods J. Lipid. Res. 10: 91.

25. Salen, G., E. H. Ahrens, Jr., and S. M. Grundy. 1970. Metabolism of $\beta$-sitosterol in man. J. Clin. Invest. 49: 952.

26. Goodman, DeW. S., R. P. Noble, and R. B. Dell 1973. Three-pool model of the long-term turnover of plasma cholesterol in man. J. Lipid Res. 14: 178.

27. Samuel, P., and S. Lieberman. 1973. Improved estimation of body masses and turnover of cholesterol by computerized input-output analysis. J. Lipid Res. 14: 189.

28. Grundy, S. M., E. H. Ahrens, Jr., G. Salen, P. H. Schreibman, and P. J. Nestel. 1972. Mechanisms of action of clofibrate on cholesterol metabolism in patients with hyperlipidemia. J. Lipid Res. 13: 531.

29. Salen, G., and A. Polito. 1972. Biosynthesis of 5 $\alpha$-cholestan-3$\beta$-ol in cerebrotendinous xanthomatosis. J. Clin. Invest. 51: 134.

30. Rosenfield, R. S., L. Hellman, and B. Zumoff. 1966. Conversion of cholesterol injected into man to cholestanol via a 3-ketonic intermediate. J. Lipid Res. 8: 16.

31. Shefer, S., S. Hauser, and E. H. Mosbach. 1966. Biosynthesis of cholestanol: $5 \alpha$-cholestan-3-one reductase in rat liver. J. Lipid Res. $7: 763$.

32. Samuel, P., W. Perl, C. M. Holtzman, N. D. Rochman, and S. Lieberman. 1972. Long-term kinetics of serum and xanthoma cholesterol radioactivity in patients with hypercholesterolemia. J. Clin. Invest. 51: 266.

33. Bhattacharyya, A. K., W. E. Conner, and A. A. Spector. 1972. Excretion of sterols from the skin of normal and hypercholesterolemic humans. Implications for sterol balance studies. J. Clin. Invest. $51: 2060$.

34. Garbutt, J. T., and T. J. Kenny. 1972. Effect of cholestyramine on bile acid metabolism in normal man. J. Clin. Invest. $51: 2781$.

35. Salen, G., and T. W. Meriwether. 1972. Chenodeoxycholic acid (CDCA) inhibits sterol biosynthesis in cerebrotendinous xanthomatosis. Clin. Res. 20: 465 (Abstr.) 